\title{
AS POLÍTICAS DE AUSTERIDADE E AS ATUAIS REFORMAS DO ESTADO BRASILEIRO: RESPOSTAS DADAS À CRISE CAPITALISTA
}

\author{
LAS POLÍTICAS DE AUSTERIDAD Y LAS ACTUALES REFORMAS DEL ESTADO \\ BRASILEÑO: RESPUESTAS DADAS A LA CRISIS CAPITALISTA
}

\section{POLITICS OF AUSTERITY AND CURRENT REFORMS OF THE BRAZILIAN STATE: ANSWERS GIVEN TO THE CAPITALIST CRISIS}

DOI: http://dx.doi.org/10.9771/gmed.v1111.32257

\author{
Aline Soares Nomeriano ${ }^{1}$ \\ Renalvo Cavalcante Silva ${ }^{2}$
}

\begin{abstract}
Resumo: As atuais políticas de austeridade adotadas por diversos países capitalistas têm rebatimento direto sobre as condições de vida e trabalho da classe trabalhadora. Tanto nos países centrais como na periferia, a exemplo do Brasil, são colocados na ordem do dia pacotes de ajuste fiscal e reformas estatais que visam retomar a taxa de lucro do capital em queda. Neste sentido, este trabalho trata-se de um estudo bibliográfico que pretende analisar a relação entre a crise capitalista e as políticas de austeridade sobre os trabalhadores no Brasil contemporâneo. Para tanto, o artigo teve como principal aporte teórico as contribuições de Marx (2013), Mészáros (2002), Netto; Braz (2011), entre outros.
\end{abstract}

Palavras-chave: crise capitalista, políticas de austeridade, trabalhadores.

Resumen: Las actuales políticas de austeridad adoptadas por diversos países capitalistas tienen rebaja directa sobre las condiciones de vida y trabajo de la clase obrera. Tanto en los países centrales como en la periferia, a ejemplo de Brasil, se colocan en el orden del día paquetes de ajuste fiscal y reformas estatales que apuntan a retomar la tasa de ganancia del capital en caída. En este sentido, este trabajo se trata de un estudio bibliográfico que pretende analizar la relación entre la crisis capitalista y las políticas de austeridad sobre los trabajadores en el Brasil contemporáneo. Para ello, el artículo tuvo como principal aporte teórico las contribuciones de Marx (2013), Mészáros (2002), Netto; (2011), entre otros.

Palabras clave: crisis capitalista, políticas de austeridad, trabajadores.

Summary: The current austerity policies adopted by various capitalist countries have a direct bearing on the living and working conditions of the working class. In both central and peripheral countries, as in Brazil, fiscal adjustment packages and state reforms are being placed on the agenda in order to retake the rate of profit of falling capital. In this sense, this work is a bibliographical study that intends to analyze the relationship between the capitalist crisis and the austerity policies on workers in contemporary Brazil. For that, the main theoretical contribution was the contributions of Marx (2013), Mészáros (2002), Netto; Braz (2011), among others.

Key words: capitalist crisis, austerity policies, workers.

\section{Introdução}

O Estado burguês vem, paulatinamente, retirando dos trabalhadores seus direitos sociais obtidos por meio de lutas históricas. Assim, vem perdendo o seu caráter público, passando a atuar apenas como gestor dos serviços ofertados à população, confirmando o seu caráter classista e reprodutor do grande capital. Todo esse processo tem sido marcado pelo avanço da extrema direita e das forças mais reacionárias (nacionais e internacionais) que defendem um extenso pacote de ajuste fiscal. 
O referido pacote vem por meio de políticas de austeridade ${ }^{3}$, que acabam por resultar em um retrocesso histórico para a classe trabalhadora. Todas elas estão na ordem do dia, o que revela a gravidade da crise capitalista, já que não atinge apenas os países periféricos, mas também os países centrais. Essas políticas, que vêm seguidas de pacotes de reformas estatais, afetam drasticamente a classe trabalhadora, tendo por finalidade o fortalecimento do capital financeiro e a redução dos impactos causados pela redução da taxa de lucro.

Para tanto, o presente trabalho foi organizado desse modo: inicialmente, analisa-se o desenvolvimento do modo de produção capitalista, suas crises e contradições. Em seguida, relaciona-se a atual crise capitalista, a neoliberalização do mundo e as políticas de austeridade. Por fim, aborda-se o ataque das atuais reformas do Estado Brasileiro sobre os trabalhadores.

\section{O desenvolvimento do modo de produção capitalista, suas crises e contradições: da fase “clássica” do imperialismo aos "anos dourados" da intervenção estatal}

O capitalismo tende a crises econômicas, o que indica seu caráter ineliminável (ou seja, algo que faz parte desse modo de produção). É o que se constata em pouco mais de um século, entre 1825 e 1937 1938 (vésperas da segunda guerra mundial), em que “[...] as fases de prosperidade econômica foram catorze vezes acompanhadas por crises [...]" (NETO; BRAZ, 2011, p. 166, grifo dos autores). Sendo a mais grave do século XIX, a que eclodiu no início dos anos de 1870 (a primeira grande depressão mundial) e no século XX, a de 1929, com a quebra da Bolsa de Nova Iorque.

De uma forma geral, nas crises capitalistas o que há é a superprodução de bens sem o escoamento necessário, isto é, sem número suficiente de consumidores:

A causa básica de tais crises é que, com a abundância, a oferta de mercadorias torna-se maior do que a demanda (as necessidades humanas) e, com isso, os preços tendem a cair, inviabilizando a produção [...] Até a Revolução Industrial, a carência garantia preços tendencialmente elevados, já que a demanda era sempre maior do que a oferta; com a abundância, a situação se inverteu e o mercado deixou de operar a favor das classes dominantes [...] (LESSA, 2013, p. 187).

Porém, o mercado produtor sempre encontra alternativa de recuperação, mesmo que provisória, havendo a retomada do ciclo econômico. Até que novamente, a produção se amplia largamente, o mercado consumidor não acompanha o crescimento (interrompendo-se a fase da prosperidade) e sobrevém novo momento de crise, recomeçando o círculo vicioso.

Nesse sentido, dentre as contradições inerentes ao capitalismo, pode-se destacar como fundamental a contradição entre a produção socializada e a apropriação privada. Ou seja, a classe trabalhadora produz toda a riqueza material da humanidade e ainda um enorme excedente, o qual é apropriado privadamente apenas pelos donos dos meios de produção. Isso configura a luta de classes e o antagonismo irreconciliável entre as duas classes fundamentais, que são o proletariado (trabalhadores) e a burguesia (capitalistas).

Percebe-se que as supracitadas crises resultam da própria dinâmica contraditória do capitalismo, sendo três as causas mais marcantes para suas eclosões: a anarquia da produção, a queda da taxa de lucro e 
o subconsumo das massas trabalhadoras, conforme Netto; Braz (2011) baseados em Marx (2013). Assim como também se constata que tais crises exercem uma função essencial ao capitalismo, que é a de perpetuálo, mesmo dentro de processos complexos e instáveis.

Em sua grandiosa obra O Capital, Marx consegue evidenciar que o capital não é algo material/tangível, mas sim uma relação social e histórica, portanto, mutável e passível de mudança. Outra característica muito identificada em suas análises é quanto ao rápido e intenso desenvolvimento das forças produtivas, como a marca registrada do modo de produção capitalista.

Após o longo processo de acumulação primitiva ${ }^{4}$, que durou por toda a transição do feudalismo ao capitalismo e primórdios desse último, pode-se identificar como antecedentes ${ }^{5}$ do estágio imperialista: a fase do capitalismo concorrencial/mercantil ${ }^{6}$, do capital usurário (este último sob a forma de juros, ambos na esfera da circulação) e do capital industrial (este na esfera da produção, a partir da Revolução Industrial). Muitas foram as principais mudanças: no âmbito político, com a completude da Revolução Burguesa (especialmente na Inglaterra e na França) e já ficando clara a função maior do Estado, que é a de assegurar a acumulação capitalista, garantir a propriedade privada e manter a "ordem pública"; no aspecto técnico, com a instauração da Revolução Industrial, processo que resultará na passagem da subsunção formal (maisvalia absoluta) para a subsunção real (mais-valia relativa) do trabalho ao capital.

No que concerne ao campo social, com as lutas de 1848 (além da Comuna de Paris, em 1871), apesar das derrotas, o operariado situa-se como sujeito revolucionário, única classe capaz de transformar radicalmente a ordem burguesa. Nesse momento de grande explosão social, a burguesia finda seu caráter revolucionário (característico da Revolução Burguesa e seus ideais libertadores) e apresenta-se como classe conservadora em toda sua essência, iniciando-se o ciclo de sua decadência ideológica ${ }^{7}$. No plano da economia, há o surgimento dos monopólios (após a primeira grande depressão econômica, iniciada em 1870):

O processo de concentração do capital implicou que, com a crise de 1870-71, as principais economias capitalistas passassem a ser dominadas por grandes grupos econômicos. São os cartéis, monopólios etc. fazendo a sua entrada em cena de modo triunfal [...] O capitalismo monopolista possui uma capacidade de investimento, de manipulação de mercados, e um poder de pressão política sobre o Estado, incomparáveis a qualquer fortuna burguesa anterior; os cartéis e monopólios passam a controlar a política econômica e a política externa dos seus Estados nacionais [...] agora, há a possibilidade de se empregar o Estado de modo muito mais imediato que no capitalismo concorrencial para atender às necessidades de reprodução do grande capital [...] (LESSA, 2013, p. 189).

Nesse mesmo período ocorre também o processo de monopolização no setor dos bancos, em que se consolida, para além dos capitais comercial e industrial, o bancário (portador de juros); o qual resultará no capital financeiro (fusão do capital dos monopólios bancários e industriais). É todo esse desenvolvimento evolutivo do capitalismo que culminará num novo estágio, o imperialismo ${ }^{8}$.

Alguns autores denominam essa fase ${ }^{9}$ de capitalismo monopolista (a exemplo de José Paulo Netto), uma vez que a forma empresarial típica é a monopólica e o capital financeiro passa a assumir certo protagonismo. 
Assim, Netto; Braz (2011) apoiados em Marx, destacam como três as causas fundamentais dos lucros nessa etapa (crescimento extraordinário do excedente econômico): a) fixação de um preço superior ao preço de mercado; b) apropriação de parte da mais-valia de setores não monopolizados pelos monopólios; c) vantagens das empresas monopolistas sobre as pequenas/médias empresas e setores nãomonopolizados. Em relação ao tipo de Estado vigente nessa etapa, tem-se o Liberal, em que o mercado prevalece quanto às decisões econômicas.

Todavia, há nesse contexto, dois grandes momentos do capitalismo de monopólios: um primeiro marcado por uma onda expansionista (até o início do século XX) e um segundo, marcado por uma longa estagnação ${ }^{10}$. Com relação a este último, para tentar contornar a crise de 192911, o presidente norteamericano Roosevelt, entre 1933 e 1937, põe em prática o New Deal (novo acordo) ou programa de intervenção estatal que fazia com que o governo controlasse os preços e a produção das indústrias e fazendas (entre outras medidas), sendo possível conter a inflação e evitar que houvesse acúmulo de estoques. Mas, em meados do século XX, entre os anos de 1939-45, eclode a Segunda Guerra Mundial.

Outras estratégias foram: a criação do Bird - Banco Internacional para a Reconstrução e Desenvolvimento, do Banco Mundial, do FMI - Fundo Monetário Internacional, do GATT (hoje OMC) Acordo Geral sobre Tarifas Aduaneiras e Comércio etc. "Outra disposição foi a obrigação de os países adotarem uma política monetária de câmbio de suas moedas indexada ao dólar (o padrão ouro-dólar)" (MONTAÑO; DURIGUETTTO, 2011, p. 152).

Entre 1944 e 1971 vigorou o acordo de Bretton Woods ou as regras para as relações comerciais e financeiras entre os países mais industrializados do mundo (44 nações aliadas). O sistema Bretton Woods foi o primeiro exemplo, na história mundial, de uma ordem monetária totalmente negociada, preparando-se para reconstruir o capitalismo mundial enquanto a Segunda Guerra Mundial ainda se espalhava. O referido acordo durou até 15 de agosto de 1971, quando os Estados Unidos, unilateralmente, acabaram com a convertibilidade do dólar em ouro, o que efetivamente levou o sistema de Bretton Woods ao colapso.

Vê-se o quanto o Estado intervém, sempre que é necessário ou que a economia capitalista pede salvamento (em suas crises cíclicas), mesmo contrariando os dogmas do pensamento liberal (de liberdade de mercado). É assim que, no período entre o fim do New Deal americano/1938 e meados dos anos 1970, passa a vigorar o chamado Estado de Bem-estar Social, na Europa e Estados Unidos.

Após a Segunda Guerra Mundial, o capitalismo investiu na reconstrução das economias afetadas, especialmente da Europa Ocidental, e vivenciou a experiência dos chamados “anos gloriosos” por cerca de trinta anos (até o início da década de 1970). Trata-se da política do Keynesianismo ou modelo do Welfare State (Estado de bem-estar social). Nesse sentido, alguns foram os mecanismos de intervenção do Estado no segundo pós-guerra: crédito para a produção em massa na grande indústria, investimento em tecnociência, em infraestrutura para a produção capitalista e o consumo, políticas públicas de pleno emprego e salário indireto para o consumo em massa.

As medidas de proteção social puderam ser concedidas ao longo desse período, paralelamente, à chamada Guerra Fria12, momento em que o sistema capitalista estava sob “ameaça” do Socialismo. Além 
disso, o Estado interventor visava amenizar os impactos das crises cíclicas de superprodução, inerentes ao referido sistema (nesse caso, gerada pelo modelo produtivo taylorista-fordista ${ }^{13}$, vigente na época).

No próximo tópico, analisaremos a relação entre a atual crise capitalista, o processo de neoliberalização do mundo e as políticas de austeridade.

\section{Neoliberalização do mundo e políticas de austeridade: respostas dadas à crise capitalista no final do século XX/início do século XXI}

Com a imagem criada de um Estado a serviço do povo, apesar da forte expansão ${ }^{14}$, as medidas citadas anteriormente, apenas conseguiram adiar por algumas décadas a próxima crise que o capitalismo estava por sofrer. Assim, com a entrada dos anos 1970, esgotou-se a referida fase expansiva e o intervencionismo estatal choca-se com limites estruturais: a crise fiscal/financeira do Estado e a alta inflação ${ }^{15}$, o que se soma à crise do petróleo ${ }^{16}$ (a partir de 1973), fazendo cair "por terra" a política keynesiana.

A resposta dos países imperialistas à referida crise fiscal e sua consequente queda vertiginosa da taxa de lucros foi impor um novo modo político-jurídico-econômico, o Estado neoliberal, cujos ideólogos e defensores ${ }^{17}$, para justificar a crise, criticavam o excesso de paternalismo do Estado de bem-estar social:

A corrente neoliberal, consolidada nos países capitalistas centrais na década de 80 com ampla hegemonia internacional, após os triunfos eleitorais de Thatcher e Reagan, e reafirmada na década de 90 com a "queda do Muro", sob uma forma mais "adocicada", centra-se no feroz ataque aos elementos de conquista sociais e trabalhistas que continha o chamado "pacto keynesiano", no Estado de Bem-Estar Social (MONTAÑO, 2010, p. 35 , grifo do autor).

Essa nova fase do sistema do capital ${ }^{18}$ caracteriza-se pela minimização do tamanho do Estado (especialmente no que se refere ao corte nos gastos sociais) o que coloca em outro patamar as políticas sociais: há um deslocamento da base que é a desigualdade social fruto da luta de classes (conflito entre capital e trabalho), para as diferenças, minorias, equidades.

A reação burguesa à referida crise, além do ajuste neoliberal, utilizou-se de largo processo de reestruturação produtiva19 ${ }^{19}$ cujo “[...] projeto restaurador viu-se resumido ao tríplice mote da 'flexibilização' (das relações de trabalho), 'desregulamentação' (das relações comerciais e dos circuitos financeiros) e da 'privatização' (do patrimônio estatal)" (NETTO, 2013, p. 21). Sendo o desemprego crônico um dos mais graves impactos da crise e dos "remédios" representados no tripé acima descrito.

Nos países centrais e, mais recentemente nos periféricos, o que tem se defendido pelos governos e na grande mídia é que o emprego estável (com toda legislação que o protegia) é algo do passado, superado pelas novas formas (flexíveis) de relações trabalhistas ${ }^{20}$. No entanto, a nosso ver, as mais recentes mudanças nessa área, precarizam ainda mais o trabalho e destroem os direitos ${ }^{21}$ históricos da classe trabalhadora.

Diante dessas recentes transformações societárias, iniciadas no final do século XX e aprofundadas no início do século XXI, decorrem alguns fenômenos que contribuem para a luta vitoriosa do capital contra o trabalho: a transferência dos papéis sociais para a sociedade civil, antes pertencentes ao Estado e a despolitização das lutas democráticas. E em relação à “questão social”, conforme ressalta Netto (2013), tal situação repercute num novo assistencialismo "[...] que satura as várias iniciativas - estatais e privadas, 
mediante as chamadas ‘parcerias público-privado' - que configuram as políticas sociais implementadas desde os anos 1980/1990 para enfrentar o quadro de pauperização contemporânea [...]” (p. 35).

Isto é, trata-se de um assistencialismo minimalista: a política social atual (principalmente na periferia do capitalismo) se circunscreve no nível dos direitos, da administração da pobreza (enfrentamento apenas da miséria e indigência) via programas de renda mínima (meramente emergenciais) que visam tão somente controlar as massas e evitar uma "explosão social".

$\mathrm{Na}$ América Latina, de uma forma geral, as políticas neoliberais foram implementadas a partir da década de 1980. As reformas de Estado, principalmente nos países periféricos, iniciaram-se na década de 1990, momento em que se deu a inserção do Brasil no ideário neoliberal22.

O Brasil dos anos 1990 vivenciou um período de "turbulência" entre as vitórias conquistadas pelo movimento da redemocratização (que resultaram na Constituição Federal de 1988) e a implementação da contrarreforma neoliberal: “A hegemonia neoliberal no Brasil tem sido responsável pela redução dos direitos sociais e trabalhistas, desemprego estrutural, precarização do trabalho, desmonte da previdência pública, sucateamento da saúde e educação” (BRAVO, 2007 apud SANTOS; RODRIGUES, 2018, p. 90).

Então, não obstante à viabilização dos movimentos sociais e das lutas democráticas realizadas ao longo dos anos 1980 (as quais apontavam condições políticas para a efetivação de medidas necessárias) o que ocorreu foi uma reversão conservadora. O argumento utilizado para a contrarreforma indicava como causa central da crise, o intervencionismo inoperante do próprio Estado e até a Carta Magna ${ }^{23}$, vista como atrasada. Todavia, como chamam atenção Santos; Rodrigues (2018):

A CF/1988 significou um grande avanço no campo das políticas sociais no cenário brasileiro. Com ela, inaugura-se um novo sistema de proteção social, e as políticas de saúde, assistência e previdência passam a integrar o Sistema de Seguridade Social, tornando-se públicas e de responsabilidade do Estado [...] A nova Constituição possui caráter inovador, pois diferentemente das constituições anteriores, apresenta características desenvolvimentistas no processo político e social no país. Ao longo dos anos, a Carta Magna vem tendo suas regras institucionais aperfeiçoadas e já passou por diversas emendas; infelizmente, a maioria das inovações tem servido muito mais para atender às demandas do mercado do que propriamente para adequar-se às exigências postas por uma realidade perpassada pela desigualdade social (p. 85).

Com a justificativa de equilibrar as contas públicas, em 1994 (início do primeiro mandato do governo FHC) é lançado o Plano Real, objetivando a estabilização monetária ${ }^{24}$ necessária à introdução das políticas neoliberais. Assim, o caminho para a "modernidade" teve ênfase nas seguintes ações: ajuste fiscal, privatização de estatais (rodovias, ferrovias, portos, aeroportos) e mudanças no âmbito da seguridade social. Como principais justificativas para o referido processo de privatização estavam a diminuição de preços para os consumidores (reduzindo a alta inflação vinda dos anos 1980) e a melhoria na qualidade dos serviços (que seriam ineficientes).

Ou seja, o referido modelo de estabilização da moeda (nos anos 1990) em países subdesenvolvidos da América Latina (a exemplo do México, da Argentina e do Brasil) acabou por impulsionar a dívida pública. Com isso, e seguindo a agenda neoliberal, houve forte desresponsabilização do Estado para com a política social, restringindo ou reduzindo direitos e transformando a referida política em ações compensatórias. 
Algumas graves consequências disso podemos citar: primeiro, entre outros aspectos, além de gerar cruel segregação entre os que podem e os que não podem pagar pelos serviços, propicia nichos lucrativos para o sistema do capital. Segundo, associado à seletividade, o referido processo consiste em assegurar o acesso aos serviços públicos apenas aos comprovadamente muito pobres. Por fim, a descentralização, não no sentido de compartilhamento entre as esferas públicas, mas sim como transferência de responsabilidades, principalmente para as instituições privadas e para as famosas Ong’s ou organizações sociais definidas como instituições públicas não-estatais.

Os governos posteriores (Era Lula 2002-2010 e na sequência, Dilma Rousseff 2011-2016) continuaram a pôr em prática o receituário neoliberal, com privatizações, cortes nos gastos sociais, política de juros altos e a consequente ampliação da dívida pública:

O quadro se agrava substancialmente com as medidas fiscais, privatizações, liberalizações e desregulamentações que vêm sendo aplicadas com mais sintonia do que podemos imaginar pelos governos federal, estaduais e por um Congresso Nacional marcado por absoluta miséria moral. Em 2015 projetou-se o maior ajuste fiscal da história do país que, em termos nominais, buscou reorientar o montante de $\mathrm{R} \$ 70$ bilhões, antes destinados a áreas essenciais, para a realização do superávit primário, isto é, para o pagamento do sistema da dívida pública (PINASSI; DUARTE, 2016) ${ }^{25}$.

Vê-se o mito do "neodesenvolvimentismo" conduzido pelos últimos governos, de coalizão de classes inconciliavelmente antagônicas: capital e trabalho. Dessa forma, o Estado burguês, como lócus de defesa dos interesses do capital, cria estratégias e reformas "necessárias" voltadas para a remediação das crises do sistema capitalista.

No último tópico, abordaremos algo que está na ordem do dia: o ataque de recentes reformas do Estado Brasileiro sobre os trabalhadores.

\section{Na ordem o dia: o ataque de reformas do Estado Brasileiro sobre os trabalhadores}

Assim, a crise capitalista contemporânea, que já afetava a economia dos Estados Unidos em 2008, foi ignorada pelo ex-presidente Luiz Inácio Lula da Silva, quando ele afirmou por via midiática que a crise chegaria ao Brasil como "uma marolinha que nem daria para esquiar"; porém, a "marolinha" ajudou a retirar do Palácio do Planalto a sua sucessora Dilma Rousseff, pelas denúncias de corrupção que começaram a atingir a partir de 2014 nomes importantes do PT no chamado esquema da Lava Jato.

$\mathrm{Na}$ sequência, várias manifestações marcaram os últimos anos do governo Dilma ${ }^{26}$, com os chamados "panelaços", comumente orquestrados pela classe dominante ${ }^{27}$ e pelas principais redes de telecomunicações, culminando no processo de impeachement:

A crise estrutural do capital (reaberta com a chamada crise das hipotecas norte-americana, em 2008) atingiu, em cheio, o primeiro e segundo governo de Dilma Rousseff. A vitória apertada nas eleições presidenciais de 2014 deu a senha para que o Judiciário à frente, juntamente com o MP, a Polícia Federal, os grandes meios de comunicação e o Legislativo conspirassem com sucesso para o impeachment. Divulgação ilegal de provas, atropelos jurídicos, a utilização como prova irrefutável do mecanismo da delação premiada (coma figura do terrorista arrependido na ditadura militar) e até a restrição à concessão do Habeas-Corpus (como também no Regime Militar) deram a tônica nos 
últimos três anos, até a prisão de Lula. Um juiz de primeira instância federal (Sérgio Moro) passou a mandar mais que seus superiores (BRASIL, s/d, p. 42).

No caso específico do Brasil, como de uma forma geral na América Latina, as formas de resolução em momentos de ameaça ou crise do sistema, foram orquestradas, em sua maioria, por golpes de Estado, patrocinados pelas grandes forças imperialistas, que muito bem definem qual é o sentido ou o papel destes países, no movimento do capitalismo. Assim, chega ao poder, dessa vez via golpe parlamentar, o vice de Dilma Rousseff, Michael Temer (PMDB) em governo interino (2016-2018):

Depois de mais de três décadas [do regime democrático-burguês brasileiro], ficou para um poder (o Judiciário), que sequer passa por um crivo de eleição popular (por mais limitada que esta seja) e também cheio de denúncias de privilégios e de corrupção, a tarefa de ser atualmente a principal instituição do regime democrático-burguês. Diante de um Executivo (Michel Temer) e de um poder Legislativo fracos, o poder Judiciário foi fundamental para respaldar ataques de interesse do capital rentista como o congelamento dos gastos por duas décadas, a Reforma Trabalhista e o aumento da contribuição previdenciária dos servidores (BRASIL, s/d, p. 42).

Todo o receituário neoliberal que vem sendo colocado em prática desde o governo Collor abriu caminho para outras reformas necessárias ao capital em crise, que na conjuntura nacional, alcançaram momento extremamente perverso de ataque aos direitos sociais e às políticas sociais, no último governo Temer; o qual promoveu, via seus agentes (câmara dos deputados e senado), a dita reforma do Estado, com manobras que atingem em sua forma mais brutal, a classe trabalhadora.

São medidas que vão desde a proteção legal para investimento privado na forma das PPP's (parcerias público-privadas), passando pela busca de equilíbrio fiscal por meio de ajuste estrutural e pelo desmonte da proteção social que acaba com o princípio da gratuidade do SUS; chegando a isenção de impostos para empresas e acesso destas a fontes privilegiadas de financiamento público.

O governo Temer mal assumia oficialmente e já começava o pacote de medidas duras e impopulares com a EC 95 (antigas PEC 241 e 55/2016), mais conhecida como a PEC do Teto de gastos ${ }^{28}$, já que define o congelamento por 20 anos dos investimentos públicos em áreas sociais, incluindo saúde, educação e segurança. Especialistas já avaliaram que ela influenciará negativamente até no salário mínimo, havendo grande desvalorização de 2016 em diante:

Se no período 2003/2016 vivenciamos um processo contrarrevolucionário conduzido pela política de coalizão de classes, a partir [de 2016] o Brasil entra em uma nova fase da contrarrevolução preventiva e prolongada, conduzida pelas frações mais agressivas e conservadoras da burguesia em sua luta pela reprodução do capital [...] (LIMA, 2017, p. 102).

A justificativa dada pelo referido governo foi a necessidade de "enxugar" as contas para pagamento da dívida pública de quase $70 \%$ do PIB. Tendo, na verdade, como única prioridade pagar banqueiros, a equipe econômica sequer indicou a realização de uma auditoria da dívida pública, que para Maria Lúcia Fattorelli (ex-auditora da Receita Federal), “é um esquema de corrupção institucionalizado”.

O resultado já está sendo refletido numa ainda maior precarização e sucateamento dos serviços públicos, como saúde, educação e assistência social. Pessoas morrendo nas filas dos hospitais cada vez mais superlotados, sem estrutura adequada e com pouquíssimos médicos. Ou seja, independentemente do partido, o Estado burguês, por meio de cada governo, segue na defesa do capital em detrimento do trabalho: 
Para os empresários, isenções fiscais e regalias; para o trabalhador, leis draconianas, como a criminalização dos movimentos sociais, leis antigreve e antiterrorismo, cujo objetivo era reprimir as manifestações dos trabalhadores de todas as formas. Além disso, as medidas de intensificação da exploração dos trabalhadores, como o ACE - acordo coletivo especial - que visa acabar com férias, $13^{\circ}$ salário e outros direitos trabalhistas conseguidos com muita luta pelos trabalhadores. (SILVA, 2018, p. 184).

Também na lista das principais medidas contra os trabalhadores está a já aprovada Lei da Terceirização no 13.429/17 - que permite as empresas públicas terceirizarem a atividade-fim principalmente para setores estratégicos como Banco do Brasil, Caixa Econômica Federal e Petrobrás. Assim como a Reforma Trabalhista (Lei $n^{\circ}$ 13.467/2017), que entrou em vigor no final de 2017, alterando a CLT (Consolidação das Leis Trabalhistas de 1943), precarizando ainda mais a classe que vive do trabalho e retirando seus direitos historicamente conquistados.

Atrelada à Reforma Trabalhista, uma grave mudança no âmbito da educação é a Reforma do Ensino Médio ${ }^{29}$ (Lei n ${ }^{\circ}$ 13.415/2017). Os filhos da classe trabalhadora, que no início dos anos 2000 foram incentivados a procurar o ensino superior (público e privado), ${ }^{30} \mathrm{com}$ a atual reforma do ensino médio, serão levados a "preferir" o ensino profissionalizante. Oficializa-se mais uma vez na educação brasileira que os trabalhadores não podem conhecer mais do que a burguesia permite que eles conheçam.

O mais recente retrocesso para a classe trabalhadora e algumas categorias de servidores públicos é a PEC da Reforma da Previdência de 2019, que acaba de ser entregue pelo poder Executivo (governo Bolsonaro) ao Congresso Nacional; com chances de ser aprovada ou ocorrerem mudanças por meio de medidas provisórias, uma vez que o trâmite de uma Proposta de Emenda Constitucional é complexo e demorado. A justificativa é de que a Previdência Social ${ }^{31}$ brasileira é deficitária, sendo justamente o contrário: o "rombo" previdenciário não existe tal como é apresentado pelos governos.

Enfim, as medidas acima citadas são apenas alguns exemplos da política de austeridade imposta nos últimos anos, uma vez que, tramitando no Senado brasileiro, são cerca de mais de cinquenta projetos de leis, que atacam os direitos sociais e trabalhistas, especialmente de algumas categorias de servidores públicos.

\section{Apontamentos finais}

Vivemos num momento histórico marcado pelo aprofundamento da barbárie, em que o sistema capitalista chega a um patamar altíssimo de produção da riqueza, às custas de estar colocando em risco de destruição, a sobrevivência da humanidade e do próprio planeta. A agenda neoliberal e os prejuízos políticos, econômicos, sobretudo, sociais produzidos dos anos 1990 à atualidade, foram acirradamente aprofundados.

A crescente retirada de direitos, cassação das liberdades e perda das conquistas civilizatórias têm induzido à classe trabalhadora a um aumento da precariedade de suas condições de vida e de trabalho. Somase a isso, a onda conservadora de extrema direita que assola o Brasil e o resto de boa parte do mundo. $\mathrm{O}$ que, mais do que nunca, exige o entendimento das contradições capitalistas e muita luta dos sujeitos individuais e coletivos diante de tais desafios. 
Sendo fundamental, portanto, que os trabalhadores e movimentos sociais se unam organizados em oposição à retirada de direitos sociais e retrocessos realizados ao longo das últimas décadas, na fase neoliberal mais aguda, sobretudo em favor de um amplo movimento mundial que siga firme na luta do trabalho contra o capital.

\section{Referências}

BRASIL, Alex. Os trinta e três anos do regime democrático-burguês brasileiro. Primavera Vermelha/Espaço Socialista, p. 38-44, s/d.

LESSA, S. Capital e Estado de bem-estar - o caráter de classe das políticas públicas. São Paulo: Instituto Lukács, 2013.

LIMA, K. Brasil em tempos de contrarrevolução. Universidade e Sociedade - ANDES, n. 59, p. 92-103, janeiro de 2017.

MANDEL, E. O capitalismo tardio. São Paulo: Abril Cultural, 1982.

MARX, K. O capital: crítica da economia política; Livro I: o processo de produção do capital. São Paulo: Boitempo, 2013.

MONTAÑO, C; DURIGUETTO, M. L. Estado, classe e movimento social. 3 ed. São Paulo: Cortez, 2011.

MONTAÑO, C. Terceiro setor e questão social - crítica ao padrão emergente de intervenção social. 6 ed. São Paulo: Cortez, 2010.

NETTO, J. P. Uma face contemporânea da barbárie. In COSTA, G; SOUZA, R. O social em perspectiva - Políticas, Trabalho, Serviço Social. Maceió: EDUFAL, 2013.

NETTTO, José Paulo; BRAZ, Marcelo. Economia política: uma introdução crítica. 7. ed. São Paulo: Cortez, 2011.

SANTOS, G. N. B. dos; RODRIGUES, F. S. S. Neoliberalismo e seus reflexos na política de saúde no Brasil. In SANTOS NETO, A. B. dos (Org.). Análise de conjuntura: a dinâmica da luta de classes no Brasil no contexto da crise do capital (Volume 1) [recurso eletrônico] Goiânia, GO: Editora Phillos, 2018.

SILVA, M. de O. Os governos petistas e a continuidade do neoliberalismo. In SANTOS NETO, A. B. dos (Org.). Análise de conjuntura: a dinâmica da luta de classes no Brasil no contexto da crise do capital (Volume 1) [recurso eletrônico] Goiânia, GO: Editora Phillos, 2018.

\footnotetext{
Notas:

${ }^{1}$ Graduada em Ciências Sociais (UFAL), Mestre em Educação (UFAL) e Doutoranda em Serviço Social (UFAL). Professora da Universidade Federal de Alagoas - Campus Arapiraca (Colegiado de Pedagogia). ORCID: http://orcid.org/0000-0002-08341649 E-mail: asnomeriano@arapiraca.ufal.br.

2 Graduado em Pedagogia (UNEAL), Mestre em Educação (UFAL) e Doutorando em Serviço Social (UFAL). Professor da Universidade Estadual de Alagoas - Campus Arapiraca (Colegiado de Pedagogia). ORCID: http://orcid.org/0000-0003-0869$\underline{6324}$ E-mail: renalvo.pedagogo@gmail.com,

${ }^{3}$ Em economia, a austeridade significa rigor teórico no controle de gastos. Uma política de austeridade é utilizada quando o nível do déficit público é considerado insustentável e é implementada através do corte de despesas, a fim de recuperar o equilíbrio fiscal (sendo o alvo preferencial, a área social, daí a queda do padrão de vida da população no curto prazo).

${ }^{4}$ Cf. MARX, K. O capital: crítica da economia política; Livro I: o processo de produção do capital. São Paulo: Boitempo, 2013.

${ }^{5}$ Entre os séculos XVIII e XIX.

${ }^{6}$ Acerca desse processo no Brasil, indicamos a leitura de: SANTOS NETO, A. B. Capital e trabalho na formação econômica do Brasil. São Paulo: Instituto Lukács, 2015.

${ }^{7}$ Cf. COUTINHO, C. N. O estruturalismo e a miséria da razão. Rio de Janeiro: Paz e Terra, 1972.
} 
${ }^{8}$ Indicamos a leitura de LENIN, V. I. Imperialismo, fase superior do capitalismo. 5 ed. São Paulo: Global, 1987. O autor sublinha que esta fase é marcada pela monopolização da economia e imenso progresso na socialização da produção, mas sobretudo, por uma enorme concentração de renda.

${ }^{9}$ Conforme a periodização de Mandel (1982), essa fase vai de 1890 a 1940.

10 Quando entra em crise o modelo liberal e entra em cena a "mão invisível" do mercado (de A. Smith) e a Lei de Say, ou Lei da oferta e da procura.

11 A crise de 1929 se deu basicamente pela superprodução nos Estados Unidos. Entre os anos de 1918 e 1928, o cenário econômico norte-americano era excelente, com muitos empregos, preço baixo, elevada produção na agricultura e a expansão do crédito, que incentivava o consumismo desenfreado. A questão foi que, nesse período, a Europa começou a se reestabelecer, o que levou a importar cada vez menos dos Estados Unidos. A indústria norte-americana passou a não ter mais para quem vender a quantidade exacerbada de mercadorias, havendo mais produtos do que procura. Isso levou a diminuição dos preços, queda da produção, e consequentemente, diminuição do PIB e aumento da inflação e do desemprego. Esses fatores provocaram a queda das ações e, sem seguida, a quebra de bolsas de valores (a exemplo da de New York).

12 Divisão do mundo em dois grandes blocos de influência econômica, ideológica e militar: capitalismo e socialismo, representados, respectivamente pelos EUA e ex-URSS.

13 Ainda na fase "clássica" do imperialismo, a "gerência científica" de Taylor foi objeto de grande desenvolvimento das forças produtivas, caracterizada pela produção em série, larga escala, especializada.

14 Às custas do aumento da taxa de exploração da classe trabalhadora e do recuo do movimento operário.

15 Seguidas da decisão norte-americana de desvincular o dólar do ouro.

${ }^{16}$ Com a alta dos preços determinada pela OPEP - Organização dos Países Exportadores de Petróleo.

17 Cf. FRIEDMAN, M. Capitalismo e liberdade. São Paulo: Nova Cultural, 1985 e HAYEK, A. O caminho da servidão. Rio de Janeiro: Instituto Liberal, 1990.

18 Somada ao fim da Guerra Fria, Queda do Muro de Berlin e ao colapso dos regimes do Leste Europeu.

${ }^{19}$ Cuja literatura sobre a temática é vasta, principalmente a fundamentada na crítica marxista.

20 Ver: FREITAS, Alessandra Rodrigues. A flexibilização dos direitos trabalhistas e a tendência de anualização da jornada de trabalho: o banco de horas em debate. In: PLANCHEREL, A; BERTOLDO, E. (Orgs). Trabalho e capitalismo contemporâneo. Maceió: EDUFAL, 2011.

${ }^{21}$ Como vem ocorrendo em vários países de capitalismo avançado e, no Brasil, especialmente a partir da atual reforma trabalhista.

22 Tratam-se dos governos: Collor (1990-1992) e Itamar Franco (1993-1994), adaptando o país ao Consenso de Washington; FHC (1995-1998 e 1999-2002), na segunda fase da investida neoliberal; LULA (2003-2006 e 2007-2010), na consolidação do neoliberalismo brasileiro; DILMA (2011-2014 e 2015-2016), com o aprofundamento do ideário neoliberal e o rebatimento da crise no setor político e social; TEMER (governo interino 2016-2018) e a intensificação da retirada de direitos sociais.

23 Apesar de seus avanços legais em 1988 e de sua legislação complementar, que veio em seguida.

${ }^{24}$ Em 1994, o real chegou a valer mais que o dólar.

25 PINASSI, M, O; DUARTE, F. A. Expansão do capital e crise estrutural no Brasil. Reflexões sobre a reestruturação política e a crise social. Passa Palavra, 12 de maio de 2016. Disponível em: http://passapalavra.info/2016/05/108248/. Acesso em 28/10/2018.

26 “As manifestações de junho de 2013 foram chamadas pelos jovens do Movimento Passe Livre (MPL) para o que seria mais uma jornada de lutas pela Tarifa Zero. No entanto, o desfecho do episódio, que acabou se tornando um divisor de águas da história recente do país, pouco guardou do apelo verdadeiramente popular e combativo daquele momento original efervescente. Uma horda de jovens reacionários, patrocinados por empresas e agências de "difusão democrática" norte-americanas, articulados à mídia do Instituto Millenium (Editora Abril, Folha de São Paulo, Estado de São Paulo e Rede Globo) e à Polícia Militar, toma as ruas com uma pauta anticorrupção moral e agressiva [...]” Disponível em http://passapalavra.info/2016/05/108248. Acesso em 23 de outubro de 2018.

27 Nesse período, surge um movimento de extrema direita chamado Movimento Brasil Livre (MBL) que assimila elementos nazifascistas e neoliberais; ou seja, ao mesmo tempo em que defendem uma política nacionalista, repressora e militarista contra aqueles que não comungam da mesma ideologia, também defendem uma política de austeridade fiscal, de privatizações, livre comércio e de redução do Estado nos benefícios sociais.

${ }^{28}$ Com inserção no texto da Constituição Federal de 1988, havendo outros projetos que visam "legalizar" esse esquema financeiro: PLP 181/2015 e PL 3337/2015 (Câmera dos Deputados), PLS 204/2016 (Senado), cujos prejuízos aos entes federados (Estados e Municípios) serão incomensuráveis, dando segurança jurídica às operações de cessão de direitos creditórios e garantindo recursos públicos para as empresas estatais não dependentes.

${ }^{29}$ Já em 2015, prevendo o absurdo que estava por vir com a tal reforma, as ocupações realizadas por estudantes secundaristas contra o desmonte da educação pública, em alguns Estados brasileiros, nos deram muitas lições de organização e de luta.

30 Por meio do processo de expansão e interiorização das universidades e institutos federais, além de programas de bolsas como FIES e PROUNI, na rede particular de ensino.

31 Acerca da relação entre previdência social e reprodução do capital, uma excelente e atualíssima leitura está em: SANTOS NETO, A. B. dos. Previdência Público-Privada e Reprodução do Capital. [recurso eletrônico] Goiânia, GO: Editora Phillos, 2018. 
